\title{
Mutant Prolactin Receptor and Familial Hyperprolactinemia
}

\author{
Paul J. Newey, D.Phil., Caroline M. Gorvin, D.Phil., Stephen J. Cleland, Ph.D., \\ Christian B. Willberg, D.Phil., Marcus Bridge, B.Sc., \\ Mohammed Azharuddin, M.B., B.S., Russell S. Drummond, M.D., \\ P. Anton van der Merwe, Ph.D., Paul Klenerman, D.Phil., Chas Bountra, Ph.D., \\ and Rajesh V. Thakker, M.D.
}

SUMMARY

Hyperprolactinemia that is not associated with gestation or the puerperium is usually due to tumors in the anterior pituitary gland and occurs occasionally in hereditary multiple endocrine neoplasia syndromes. Here, we report data from three sisters with hyperprolactinemia, two of whom presented with oligomenorrhea and one with infertility. These symptoms were not associated with pituitary tumors or multiple endocrine neoplasia but were due to a heterozygous mutation in the prolactin receptor gene, PRLR, resulting in an amino acid change from histidine to arginine at codon 188 (His188Arg). This substitution disrupted the high-affinity ligand-binding interface of the prolactin receptor, resulting in a loss of downstream signaling by Janus kinase 2 (JAK2) and signal transducer and activator of transcription 5 (STAT5). Thus, the familial hyperprolactinemia appears to be due to a germline, loss-of-function mutation in PRLR, resulting in prolactin insensitivity.

From the Academic Endocrine Unit, Radcliffe Department of Medicine (P.J.N., C.M.G., R.V.T.), Peter Medawar Building for Pathogen Research, Nuffield Department of Medicine (C.B.W., P.K.), Oxford Molecular Pathology Institute, Sir William Dunn School of Pathology (M.B., P.A.M.), and the Structural Genomics Consortium (C.B.), University of Oxford, Oxford, and Glasgow Royal Infirmary, Glasgow (S.J.C., M.A., R.S.D.) - all in the United Kingdom. Address reprint requests to Dr. Thakker at the Radcliffe Department of Medicine, University of Oxford, Oxford Centre for Diabetes, Endocrinology, and Metabolism, Churchill Hospital, Oxford OX3 7LJ, United Kingdom, or at rajesh .thakker@ndm.ox.ac.uk.

Drs. Newey and Gorvin contributed equally to this article.

This article was published on November 6, 2013, at NEJM.org.

N Engl J Med 2013;369:2012-20.

DOI: 10.1056/NEJMoal307557

Copyright @ 2013 Massachusetts Medical Society
P ROLACTIN, A HORMONE THAT IS SECRETED PREDOMINANTLY BY LACTOtrophs in the anterior pituitary gland, is required for the induction and maintenance of lactation in the peripartum and postpartum periods. ${ }^{1}$ However, hyperprolactinemia unrelated to pregnancy occurs in approximately 0.1 to $0.3 \%$ of the general population ${ }^{2,3}$ and may result in infertility, hypogonadism, and galactorrhea. Such nonphysiologic hyperprolactinemia is caused mainly by drugs or by tumors in the anterior pituitary gland, which are usually identifiable by means of magnetic resonance imaging (MRI). Approximately $50 \%$ of cases of nonphysiologic hyperprolactinemia are due to prolactinomas ${ }^{4}$; a smaller percentage is due to lesions in the pituitary stalk or systemic disorders (Table S1 in the Supplementary Appendix, available with the full text of this article at NEJM.org). ${ }^{2,3}$ However, 10 to $60 \%$ of patients with hyperprolactinemia who undergo investigation for a pituitarybased lesion have normal findings on MRI of the pituitary gland, ${ }^{2,3,5,6}$ and these patients with idiopathic hyperprolactinemia may have a microadenoma below the limit of MRI detection ( $<2 \mathrm{~mm}$ in diameter) or a different cause of the disorder. ${ }^{2}$

The occurrence of idiopathic hyperprolactinemia in families has suggested a genetic cause, although investigations for mutations of the multiple endocrine neoplasia type 1 gene (MEN1), which are associated with prolactinomas, have not detected abnormalities. ${ }^{7}$ We hypothesized that familial idiopathic hyperprolactinemia may be due to either abnormalities of the prolactin gene (PRL), with the secretion of biologically inactive forms of prolactin, or to prolactin insensitivity 
caused by a mutation of the prolactin receptor gene (PRLR). Such prolactin insensitivity would be analogous to growth hormone insensitivity and parathyroid hormone resistance resulting in pseudohypoparathyroidism, which are associated with high serum hormone concentrations and have various clinical manifestations. ${ }^{8,9}$ We therefore performed genetic studies to determine whether there were PRL or PRLR mutations in three sisters with familial idiopathic hyperprolactinemia (Table 1).

\section{CASE REPORTS}

The proband (Family Member II.2) (Fig. 1) was a 41-year-old woman with a 2-year history of oligomenorrhea and menorrhagia who was found to have idiopathic hyperprolactinemia (prolactin level, $186.3 \mathrm{ng}$ per milliliter [3950 mU per liter]; normal value, $<29.7 \mathrm{ng}$ per milliliter $[630 \mathrm{mU}$ per liter]) (Table 1). Between 18 and 31 years of age, she had borne four children, and after the cessation of breast-feeding after each pregnancy, she had required dopamine agonist therapy to terminate persistent galactorrhea. She had no clinical features of hypopituitarism and was not taking any medication. MRI of the pituitary gland was normal (Fig. S1 in the Supplementary Appendix).

Two years after the proband received her diagnosis, her 38-year-old sister (Family Member II.4) presented with a 3-year history of primary infertility. She had persistent hyperprolactinemia (prolactin level, $125 \mathrm{ng}$ per milliliter [2643 mU per liter]), with a normal MRI of the pituitary gland and no other clinical findings (Table 1). Evaluation of family members identified another sister (Family Member II.3), 43 years of age, with longstanding oligomenorrhea, who had hyperprolactinemia (prolactin level, $99 \mathrm{ng}$ per milliliter [2100 mU per liter]), with a normal MRI of the pituitary gland (Table 1). In addition, the proband's father (Family Member I.1) and son (Family Member III.2) were found to have persistent hyperprolactinemia, with prolactin levels of $20 \mathrm{ng}$ per milliliter (429 $\mathrm{mU}$ per liter) and $21 \mathrm{ng}$ per milliliter (439 mU per liter), respectively (normal reference value in men, $<19$ ng per milliliter [400 mU per liter]) (Table S2 in the Supplementary Appendix).

The family members with hyperprolactinemia did not have MEN1 mutations (Table 1) or immunologic abnormalities (Table S3 in the Sup- plementary Appendix). The latter may have been expected from suggested roles in immunity of prolactin and the prolactin receptor, which is a member of the class 1 cytokine receptor family that signals predominantly through the JAK2STAT5 pathway (Fig. S2 in Supplementary Appendix). ${ }^{14,15}$ Four other family members had normal prolactin levels (Fig. 1, and Table S2 in the Supplementary Appendix).

\section{METHODS}

\section{PATIENTS, FAMILY MEMBERS, AND CONTROLS}

Informed consent for DNA sequence analysis was obtained from 124 persons (oral consent from 110 unrelated persons and written consent from 14 persons [ 9 family members and 5 unrelated normal persons]) with the use of protocols approved by local and national research ethics committees. DNA samples from the 110 unrelated persons were used as controls for assessing the presence of sequence polymorphisms. A total of 4 of the 5 family members with hyperprolactinemia and all 5 unrelated normal persons also provided written consent for immunologic studies.

\section{MUTATIONAL ANALYSIS}

DNA sequence analysis was performed with the use of leukocyte DNA and gene-specific primers (Table S4 in Supplementary Appendix). Polymorphic variants were identified from public databases (Table S5 in the Supplementary Appendix).

\section{STRUCTURAL AND FUNCTIONAL STUDIES OF PRLR MUTATIONS}

Mutations were introduced by means of sitedirected mutagenesis into the pdEYFP-PRLR construct (Source Bioscience), which expresses the normal prolactin receptor, and human embryonic kidney 293 (HEK293) cells transiently transfected with nonmutant or mutant PRLR constructs. Phosphorylated JAK2-STAT5 was assessed by means of Western blot analysis and a STAT5-amplified luminescence proximity homogeneous assay (AlphaScreen, PerkinElmer), and STAT5-dependent gene expression was studied with the use of the cytokine-inducible SRC homology 2 domain protein (CISH) pGL4.10 reporter vector and dual luciferase reporter assay, as described previously. ${ }^{16}$ Protein sequence alignments and three-dimensional modeling were performed with the use of ClustalW software and the PyMOL Molecular Graphics 


\begin{tabular}{|c|c|c|c|}
\hline Characteristic & Family Member II.2 & Family Member II.3 & Family Member II.4 \\
\hline Age at presentation (yr) & 41 & 43 & 38 \\
\hline Clinical presentation & Oligomenorrhea & Oligomenorrhea & Infertility \\
\hline Gravida & 4 & 0 & 0 \\
\hline Parity & 4 & 0 & 0 \\
\hline Body-mass index $\uparrow$ & 27.8 & 33.3 & 30.5 \\
\hline Menarche (yr) & 15 & 15 & 13 \\
\hline Thelarche (yr) & 14 & 14 & 12 \\
\hline Current medication & None & $\begin{array}{l}\text { Mirtazapine, diazepam, } \\
\text { and pizotyline }\end{array}$ & None \\
\hline Prolactin level $(\mathrm{ng} / \mathrm{ml}) \ddagger$ & $136-186$ & $95-99$ & $102-158$ \\
\hline Macroprolactin level』 & Negative & Negative & Negative \\
\hline Luteinizing hormone level (U/liter) 9 & 2.0 & 3.8 & 2.0 \\
\hline Follicle-stimulating hormone level (U/liter)\| & 3.3 & 5.6 & 5.6 \\
\hline Estradiol level $(\mathrm{pg} / \mathrm{ml}) * *$ & 39 & 129 & 80 \\
\hline Thyrotropin level (mU/liter) $\dagger^{\dagger} \dagger$ & 2.7 & 4.1 & 1.9 \\
\hline Free thyroxine level $(\mathrm{ng} / \mathrm{dl})+$ & 0.9 & 1.2 & 1.2 \\
\hline Progesterone level at day $21(\mathrm{ng} / \mathrm{ml}) \int \mathbb{\int}$ & NA & NA & 17 \\
\hline Results of MRI of the pituitary gland & Normal & Normal & Normal \\
\hline Results of transvaginal ultrasonography & $\begin{array}{l}\text { Normal ovaries and } \\
\text { no PCOS }\end{array}$ & $\begin{array}{l}\text { Corpus luteum cyst and } \\
\text { no PCOS }\end{array}$ & $\begin{array}{l}\text { Corpus luteum cyst and } \\
\text { no PCOS }\end{array}$ \\
\hline Response to dopamine agonist $₫ 9$ & $\begin{array}{l}\text { Prolactin level normalized } \\
\text { with cabergoline, } \\
0.5 \mathrm{mg} / \mathrm{wk}\end{array}$ & No treatment & $\begin{array}{l}\text { Prolactin level normalized } \\
\text { with quinagolide, } \\
75 \mu \mathrm{g} / \text { day }\end{array}$ \\
\hline
\end{tabular}

* Family Member II.2 is the proband; Family Members II.3 and II.4 are the proband's sisters. The patients did not have any clinical or serum biochemical abnormalities related to multiple endocrine neoplasia type 1 (MENI). DNA sequence analysis did not identify any mutations of MEN1 or the aryl hydrocarbon-interacting protein gene (AIP), which is associated with the familial isolated pituitary adenoma syndrome. The occurrence of marked hyperprolactinemia (prolactin level, $>95 \mathrm{ng}$ per milliliter [2000 $\mathrm{mU}$ per liter]), which was not associated with pituitary abnormalities or another identifiable cause but which resulted in various clinical expressions that included oligomenorrhea and infertility, suggested that this disorder of familial isolated hyperprolactinemia may be due to prolactin insensitivity. For Family Member II.4, the samples for luteinizing hormone, follicle-stimulating hormone, estradiol, and progesterone were obtained on day 21 of the cycle (i.e., during the luteal phase). It is not possible to state what stage of the cycle Family Members II.2 and II.3 were in because they have oligomenorrhea (i.e., infrequent, irregular menstrual cycles), so the timing of the blood samples is uncertain. MRI denotes magnetic resonance imaging, NA not applicable, and PCOS the polycystic ovary syndrome.

$\dagger$ The body-mass index is the weight in kilograms divided by the square of the height in meters.

7 The range of serial readings at the time of diagnosis is shown (normal value, $<29.7 \mathrm{ng}$ per milliliter $[630 \mathrm{mU}$ per liter]). To convert values for prolactin to milliunits per liter, multiply by 21.2 .

$\int$ The polyethylene glycol precipitation assay was performed to rule out the presence of clinically significant amounts of macroprolactin.

9 The normal ranges are as follows: follicular phase, 2 to $13 \mathrm{U}$ per liter; mid-cycle phase, 34 to $115 \mathrm{U}$ per liter; and luteal phase, 1 to $16 \mathrm{U}$ per liter.

$\|$ The normal ranges are as follows: follicular phase, 3 to $8 \mathrm{U}$ per liter; mid-cycle phase, 2 to $16 \mathrm{U}$ per liter; and luteal phase, 1 to $5 \mathrm{U}$ per liter.

*** The normal ranges are as follows: follicular phase, 21 to $251 \mathrm{pg}$ per milliliter (77 to 920 pmol per liter); midcycle phase, 38 to $648 \mathrm{pg}$ per milliliter (140 to $2370 \mathrm{pmol}$ per liter); and luteal phase, 21 to $312 \mathrm{pg}$ per milliliter ( 80 to $1150 \mathrm{pmol}$ per liter). To convert values for estradiol to picomoles per liter, multiply by 3.671 .

†t The normal range is 0.4 to $5.0 \mathrm{mU}$ per liter.

The normal range is 0.7 to $1.6 \mathrm{ng}$ per deciliter ( 9 to $21 \mathrm{pmol}$ per liter). To convert values for free thyroxine to picomoles per liter, multiply by 12.87 .

If The normal value is greater than $6 \mathrm{ng}$ per milliliter ( $19 \mathrm{nmol}$ per liter), which is consistent with the range associated with ovulation (6 to $23 \mathrm{ng}$ per milliliter [19 to $73 \mathrm{nmol}$ per liter]). To convert values for progesterone to nanomoles per liter, multiply by 3.180 .

99 The hyperprolactinemia in these women responded to dopamine agonist therapy, thereby indicating preservation of dopamine D2-receptor signaling; this is consistent with the findings in mice null for the prolactin receptor gene, which had reduced hypothalamic dopaminergic tone, indicating a probable loss of negative feedback. ${ }^{10}$ 
Figure 1. Missense Mutation in the Prolactin Receptor Gene, PRLR, Resulting in a Change from Histidine to Arginine at Codon 188, and Its Location within a Three-Dimensional Model of the Prolactin Receptor.

Panel A shows the predicted outcome of DNA sequence analysis, which revealed an A-to-G substitution in the proband (Fig. S3 in the Supplementary Appendix). The A-to-G substitution at codon 188 of the mature protein is predicted to result in a missense amino acid change from histidine (His) to arginine (Arg) and in a loss of an Ncol restriction endonuclease site (C/CATGG). Panel B shows the Ncol restriction maps of nonmutant and mutant polymerase-chain-reaction products. Panel $\mathrm{C}$ shows the use of $\mathrm{Ncol}$ to confirm the A-to-G substitution and to show its cosegregation with disease and its absence in two alleles from each of 110 unrelated normal persons ( $\mathrm{N} 1$ and $\mathrm{N} 2$ are two representatives of these 110 unrelated normal persons). Data from three of the four children of the proband (Family Member II.2; arrow) who were available are shown. The age at the time of genetic testing is shown. Squares indicate male family members, and circles female family members. Filled symbols indicate affected persons, and open symbols unaffected persons; the open symbol with the dot indicates a mutation carrier with a normal prolactin level. $\mathrm{S}$ denotes size marker. Panel $\mathrm{D}$ shows a three-dimensional model of the extracellular domains of the prolactin receptor that is based on the crystal structure of prolactin (PRL; green) bound to the dimerized prolactin receptor, ${ }^{11}$ indicated as prolactin receptor 1 (PRLR1; blue) and prolactin receptor 2 (PRLR2; maroon). The Hisl88 residue of prolactin receptor 1 (red dashed circle) occurs within the high-affinity (nanomolar range) binding site-l interface; the Hisl88 residue of prolactin receptor 2 (black dashed circle) is not at the ligand-binding sites but may establish a van der Waals interaction between domains 1 and 2 (D) and D2, respectively) and be involved in a ligand-induced conformational change that is important for receptor activation. ${ }^{11,12}$ Panel E shows that His 188 forms a noncovalent bond with Aspl83 in prolactin and, along with additional histidine residues from prolactin, including His 180 , contributes a critical imidazole group that stabilizes the ligand-receptor interaction. ${ }^{13}$ Panel F shows that the mutant Arg188 results in disruption to the prolactin receptor 1 binding site 1 interface through loss of the noncovalent bond with Aspl83 in prolactin and loss of the key imidazole group.

System, version 1.6 (Schrödinger), respectively. $\mathrm{T}$ cells were evaluated from four patients and five normal controls.

\section{RESULTS}

\section{MUTATIONAL ANALYSIS OF PRL AND PRLR}

DNA sequence analysis of PRL and PRLR in the proband and in an unrelated normal person did

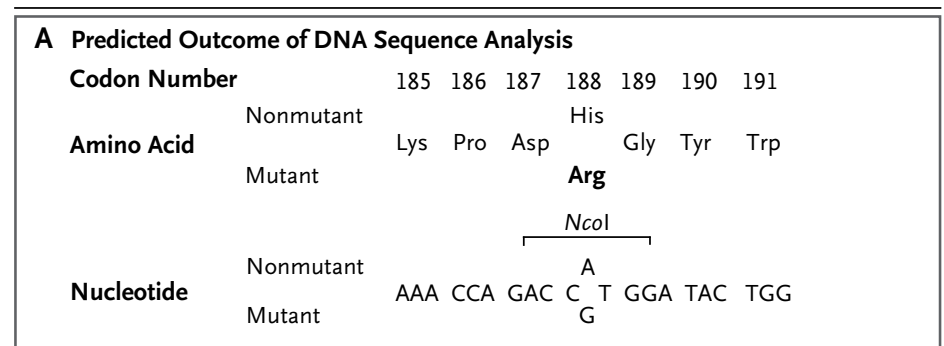

B Ncol Restriction Maps
Nonmutant $\underset{\text { Mutant }}{\longrightarrow} \quad 158 \mathrm{bp} \quad$ Ncol

C Confirmation of Testing

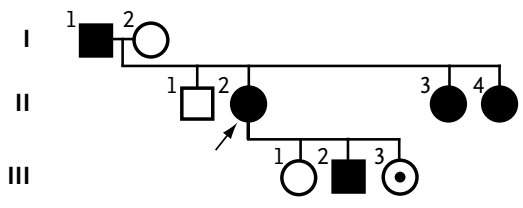

$\begin{array}{lllllllllllll}\text { I.1 } & \text { I.2 } & \text { II.1 } & \text { II.2 } & \text { III.1 III.2 } & \text { III.3 } & \text { II. } & \text { II. } & \text { N1 } & \text { N2 } & \text { S }\end{array}$

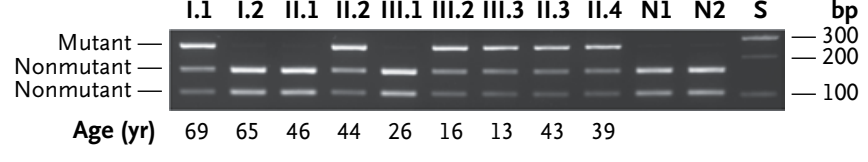

D Extracellular Domains of Prolactin Receptor
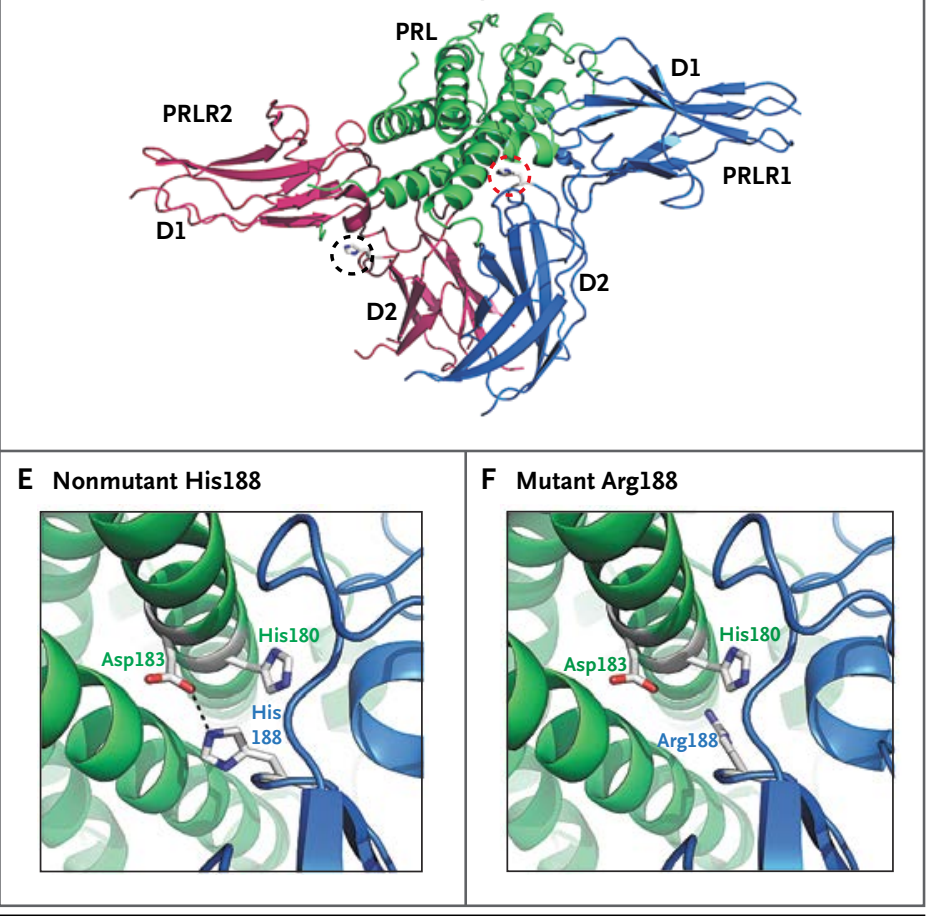

not detect $P R L$ abnormalities but did identify a heterozygous A-to-G substitution at c.635 in PRLR in the proband (Fig. 1A, and Fig. S3 in the Supplementary Appendix). This A-to-G substitution resulted in a His188Arg substitution (Fig. 1A) within 
the mature receptor, which lacks the 24-aminoacid signal peptide, and a loss of an NcoI restriction endonuclease site that was used to confirm the abnormality and show its cosegregation with hyperprolactinemia in the family (Fig. 1B and 1C).

Family members with normal prolactin levels were homozygous for nonmutant alleles, whereas affected family members were heterozygous, with 1 nonmutant allele and 1 mutant allele, which is consistent with an autosomal dominant inheritance for the disease. A mutation carrier (Family Member III.3), who was 13 years of age and prepubertal at the time of testing, did not have hyperprolactinemia, probably owing to an age-related penetrance for the disease, as observed in the case of other autosomal dominant disorders, as well as in Prlr-null mice..$^{10,17}$ In addition, the absence of this DNA sequence abnormality in 2 alleles from each of 110 controls (Fig. 1C) matched for ethnic group and in more than 13,000 alleles from databases (Table S5 in the Supplementary Appendix), together with the conservation of the His188 residue in all lactating mammal and marsupial orthologues (Fig. S3 in the Supplementary Appendix), indicates that the His188Arg abnormality probably represents a PRLR mutation rather than a polymorphic variant.

\section{PREDICTION OF EFFECTS OF THE PRLR MUTATION}

Crystallographic and in vitro studies have identified a critical role for His188, which lies within the extracellular domain, in affecting the function of the prolactin receptor. ${ }^{13,18,19}$ Prolactin interacts with each extracellular domain of the dimeric prolactin receptor, first by means of a high-affinity (nanomolar range) binding site 1 , and second, by means of a low-affinity (micromolar range) binding site 2 (Fig. 1D). ${ }^{11,14,18}$ His188 is found at the interface of the high-affinity binding site $1,{ }^{12,13,18}$ where it forms a polar contact (i.e., a noncovalent bond) with prolactin (Fig. 1E) and contributes to a four-member histidine ring, formed by His188 in the prolactin receptor and three histidines of prolactin (His27, His30, and His180), which stabilizes ligand binding and determines the $\mathrm{pH}$ dependence of receptor activation. ${ }^{13}$

Structural modeling of the PRLR mutation associated with familial idiopathic hyperprolactinemia, which results in the His188Arg substitution, predicts the loss of both the polar contact with Asp183 in prolactin and the critical imidazole ring that contributes to the high-affinity binding site 1 (Fig. 1F). The importance of this histidine ring has also been observed in studies of engineered mutants showing that a change from histidine to alanine at codon 188 (His188Ala) in the prolactin receptor results in a reduction in ligand binding by a factor of approximately 100 at physiologic $\mathrm{pH} .{ }^{13}$ In addition, mutant prolactin that shows a change from histidine to aspartic acid at codon 180 (His180Asp) results in a complete loss of ligand binding. ${ }^{13}$

\section{FUNCTIONAL CHARACTERIZATION OF HISI88ARG MUTANT}

Three-dimensional modeling predicted that the His188Arg substitution would result in a loss of function of the prolactin receptor. To investigate this possibility, we used HEK293 cells, which express components of the JAK2-STAT5 pathway and have been used previously as a model for assessing PRLR variants. ${ }^{20}$ HEK293 cells that were transfected with nonmutant and mutant PRLR constructs had similar levels of expression and cellular localization of the respective prolactin receptors (nonmutant His188 and mutant Arg188 or Ala188) (Fig. 2A, and Fig. S4 in the Supplementary Appendix).

However, nonmutant His188, but not mutant Arg188 or Ala188, prolactin receptors showed a significant increase in phosphorylated JAK2 and STAT5A when treated with prolactin (Fig. 2A and 2B, and Fig. S5 and S6 in the Supplementary Appendix). Thus, the mutant His188Arg substitution that is associated with familial idiopathic hyperprolactinemia resulted in a loss of function. Prolactin treatment did not induce any of the following effects: activation of the mitogen-activated protein kinase or extracellular signal-regulated kinase pathways in HEK293 cells transfected with nonmutant or mutant PRLR constructs; proliferation of phytohemagglutinin-stimulated or nonstimulated peripheral-blood mononuclear cells, helper T (CD4) cells, or cytotoxic T (CD8) cells isolated from patients with the mutant His188Arg prolactin receptor; or expression of CD69 or CD25, which are early T-cell activation markers, in these phytohemagglutinin-stimulated and nonstimulated cells (Fig. S6, S7, and S8 in the Supplementary Appendix).

Therefore, we performed further time-course 


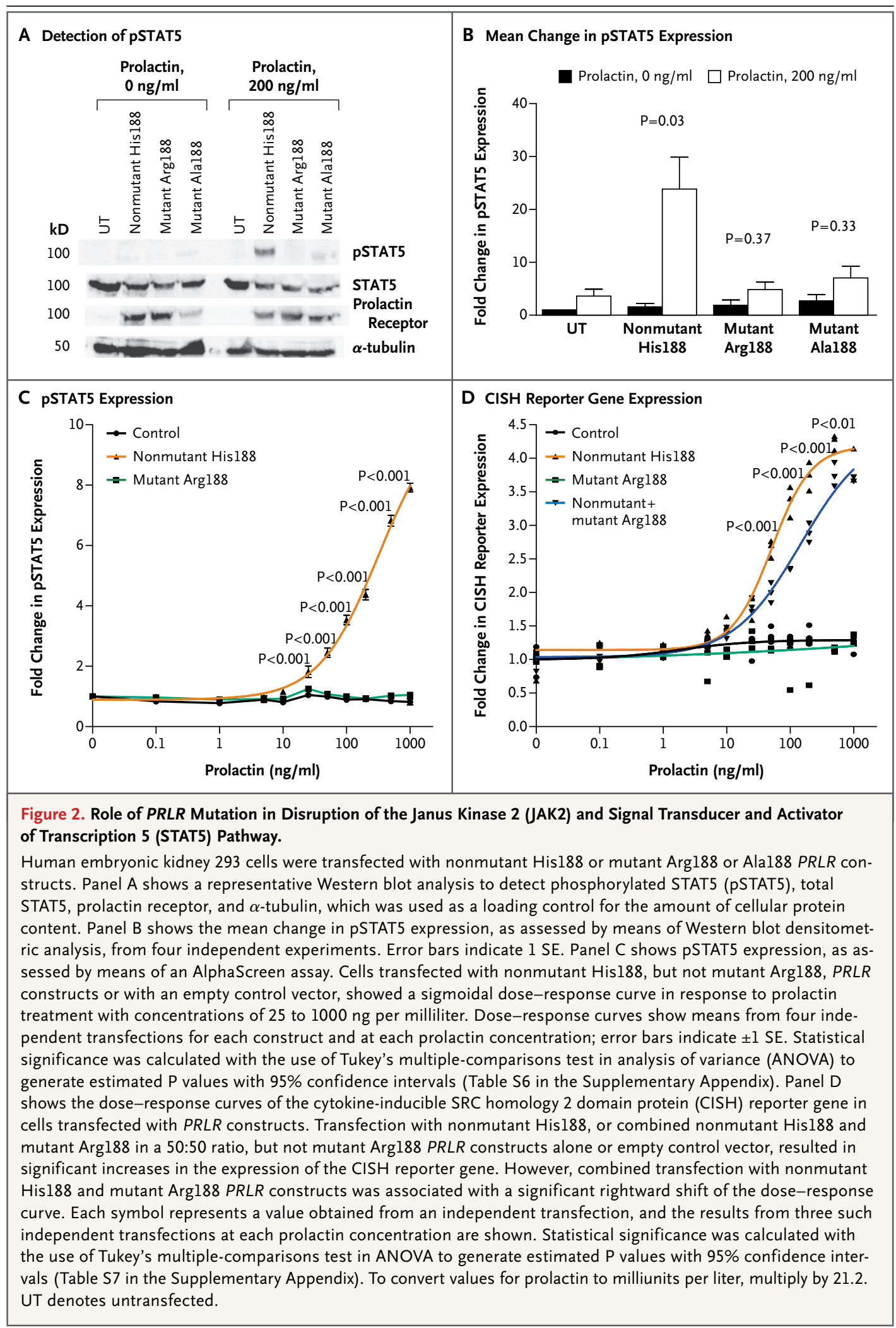

N ENGLJ MED 369;21 NEJM.ORG NOVEMBER 21, 2013

The New England Journal of Medicine

Downloaded from nejm.org on November 19, 2015. For personal use only. No other uses without permission. 
and dose-response studies only on the JAK2STAT5 signaling cascade. Prolactin stimulation of HEK 293 cells that had been transfected with nonmutant His188, but not mutant Arg188, PRLR constructs induced STAT5 phosphorylation over a range of time periods and at physiologically relevant concentrations (Fig. 2C, and Fig. S9 and S10 and Table S6 in the Supplementary Appendix). Moreover, cotransfections with nonmutant His188 and mutant Arg188 PRLR constructs resulted in a reduction of STAT5 phosphorylation, which was consistent with haploinsufficiency or an inhibitory action of the mutant prolactin receptor on the nonmutant receptor, which is referred to as a dominant-negative action of the mutant prolactin receptor (Fig. S10 in the Supplementary Appendix).

In addition to these effects on STAT5 phosphorylation, the His188Arg substitution associated with familial idiopathic hyperprolactinemia had similar effects on STAT5-mediated gene expression. Thus, 24 hours after the stimulation of transfected HEK293 cells with prolactin, nonmutant His188, but not mutant Arg188, prolactin receptors resulted in the increased expression of a CISH reporter gene, thereby confirming the loss-of-function effects of the mutant Arg188 prolactin receptor (Fig. S10 in the Supplementary Appendix). Cotransfection with nonmutant His188 and mutant Arg188 PRLR constructs resulted in a reduction of CISH reporter expression, which is consistent with a loss of function and a probable dominant-negative action of the mutant prolactin receptor (Fig. 2D, and Fig. S10 and Table S7 in the Supplementary Appendix).

\section{DISCUSSION}

Our results show that a germline PRLR mutation, which results in a loss of function, is a cause of familial idiopathic hyperprolactinemia, a condition that is associated with oligomenorrhea and infertility. The familial idiopathic hyperprolactinemia-associated His188Arg substitution in the prolactin receptor, which leads to prolactin insensitivity, is located in the extracellular domain and affects a histidine residue, which is within the high-affinity ligand-binding interface and is critical for prolactin-receptor function. ${ }^{13,18}$ This PRLR mutation did not result in altered immune function, a finding that is consistent with findings in Prlr-null mice that indicate that prolactin is not an obligate lymphopoietic hormone. ${ }^{21,22}$

To date, one other nonsynonymous PRLR variant, causing a change from isoleucine to leucine at codon 146 in the extracellular domain of the mature protein and resulting in an increased basal JAK2-STAT5 signaling in vitro, has been reported in women with benign breast fibroadenomas. ${ }^{20}$ However, the in vivo significance of this variant in breast disease remains to be established, because it is also reported to be a common polymorphism, occurring in approximately $5 \%$ of European American populations.

The extracellular domain is a common location for mutations affecting cytokine receptors, including the growth hormone receptor, in which mutations effecting inactivation result in growth hormone insensitivity. ${ }^{8}$ Persons with mutations resulting in the homozygous or compound heterozygous states of the growth hormone receptor gene have the severe growth hormone-insensitivity phenotype of Laron dwarfism, whereas persons with mutations resulting in the heterozygous state of the growth hormone receptor gene may have milder phenotypes of idiopathic short stature, ${ }^{8}$ thereby suggesting that familial idiopathic hyperprolactinemia may be the milder variant of a continuum of phenotypes that are due to PRLR mutations.

The hyperprolactinemia in this pedigree was found only in postpubertal family members, and the serum prolactin concentrations were higher in women than in men, findings that are consistent with those in studies in Prlr-null mice. ${ }^{10,23}$ Substantial hyperprolactinemia developed in Prlr-null mice in adulthood (i.e., 6 months of age or older), with infertile female mice having serum prolactin concentrations that were 5 to 10 times as high as those in male mice..$^{10,23}$ These observations suggest a role for sex-specific factors, such as increased estrogen levels during puberty, in determining the onset and severity of hyperprolactinemia. ${ }^{1}$ The onset of postpubertal hyperprolactinemia, with a continuing age-related increase in serum concentrations of prolactin, may also provide a possible explanation for the observed variation in fertility among these three sisters; one sister had, between 18 and 31 years of age, four successful pregnancies with lactation, and the other two sisters, who were 38 and 43 years of age at the time of the study, had primary infertility and oligomenorrhea, respec- 
tively. Hyperprolactinemia is known to induce hypogonadism owing to the loss of hypothalamic pulsatile secretion of the gonadotropinreleasing hormone; thus, the marked increase in age-related serum concentrations of prolactin in older women ( $>35$ years of age) with familial idiopathic hyperprolactinemia may contribute to the observed oligomenorrhea and infertility. ${ }^{1,24}$ Younger postpubertal women with this condition may remain fertile until the onset of severe hyperprolactinemia.

However, the 38-year-old sister described here had infertility but normal ovulatory cycles, thereby implicating another role for prolactin and the prolactin receptor in regulating fertility. Indeed, prolactin and the prolactin receptor have been reported to have roles in the luteal phase and peri-implantation period, and abnormalities of circulating prolactin have been associated with early pregnancy loss. ${ }^{1,24,25}$ Furthermore, the balance among the normal prolactin-receptor homodimers, mutant homodimers, and heterodimers within cells of the hypothalamic-pituitary-gonadal axis may also contribute to these phenotypic variations.

The absence of abnormal findings on MRI of the pituitary gland in the sisters reported here contrasts with findings in female Prlr-null mice, which had pituitary hyperplasia by 6 months of age and large tumors by late adulthood (i.e., 14 months of age), as compared with male Prlr-null mice, which had moderate pituitary enlargement only at 18 to 21 months of age. ${ }^{10}$ However, the three sisters are only in their 30 s or 40 s, so it seems plausible that they may have pituitary hyperplasia that is still below the limit of detection on MRI or that such abnormalities may develop in later life.

In conclusion, we identified a human germline PRLR mutation that effects a loss of function of the prolactin receptor and results in familial isolated hyperprolactinemia, a condition that is associated with oligomenorrhea and infertility.

Supported by a grant (G1000467/2010, to Drs. Newey, Gorvin, and Thakker) from the United Kingdom Medical Research Council, funding from the National Institute for Health Research (NIHR) Oxford Biomedical Research Centre Programme (to Drs. Newey, Willberg, Klenerman, and Thakker), an NIHR Senior Investigator Award (to Dr. Klenerman), and a grant (WT091663MA, to Dr. Klenerman) from the Wellcome Trust. The GO Exome Sequencing Project of the National Heart, Lung, and Blood Institute and its ongoing studies produced and provided exome variant calls for comparison (the Lung GO Sequencing Project [HL-102923], the Women's Health Initiative Sequencing Project [HL-102924], the Broad GO Sequencing Project [HL102925], the Seattle GO Sequencing Project [HL-102926], and the Heart GO Sequencing Project [HL-103010]).

Disclosure forms provided by the authors are available with the full text of this article at NEJM.org.

We thank Leighton Walker for serving as a consultant neuroradiologist and reviewing magnetic resonance images, Donna Chantler for biochemical analyses, Treena Cranston for analysis of the multiple endocrine neoplasia type 1 gene by means of multiplex ligation-dependent probe amplification, and Oleg Federov for facilitating the use of a plate reader for AlphaScreen assays.
REFERENCES

1. Ben-Jonathan N, LaPensee CR, LaPensee EW. What can we learn from rodents about prolactin in humans? Endocr Rev 2008;29:1-41.

2. Melmed S, Casanueva FF, Hoffman $\mathrm{AR}$, et al. Diagnosis and treatment of hyperprolactinemia: an Endocrine Society clinical practice guideline. J Clin Endocrinol Metab 2011;96:273-88.

3. Klibanski A. Prolactinomas. N Engl J Med 2010;362:1219-26. [Erratum, N Eng] J Med 2010;362:2142.]

4. Melmed S. Pathogenesis of pituitary tumors. Nat Rev Endocrinol 2011;7:257-66.

5. Famini P, Maya MM, Melmed S. Pituitary magnetic resonance imaging for sellar and parasellar masses: ten-year experience in 2598 patients. J Clin Endocrinol Metab 2011;96:1633-41.

6. Souter I, Baltagi LM, Toth TL, Petrozza JC. Prevalence of hyperprolactinemia and abnormal magnetic resonance imaging findings in a population with infertility. Fertil Steril 2010;94:1159-62.

7. Jakobovitz-Picard O, Olchovsky D, Berezin M, et al. Mutation analysis of the MEN1 gene in Israeli patients with MEN1 and familial isolated hyperprolactinemia. Hum Mutat 2000;16:269.

8. David A, Hwa V, Metherell LA, et al. Evidence for a continuum of genetic, phenotypic, and biochemical abnormalities in children with growth hormone insensitivity. Endocr Rev 2011;32:472-97.

9. Levine MA. Pseudohypoparathyroidism: from bedside to bench and back. J Bone Miner Res 1999;14:1255-60.

10. Schuff KG, Hentges ST, Kelly MA, et al. Lack of prolactin receptor signaling in mice results in lactotroph proliferation and prolactinomas by dopamine-dependent and -independent mechanisms. J Clin Invest 2002;110:973-81.

11. van Agthoven J, Zhang C, Tallet E, et al. Structural characterization of the stem-stem dimerization interface between prolactin receptor chains complexed with the natural hormone. J Mol Biol 2010;404:112-26.

12. Broutin I, Jomain JB, Tallet E, et al. Crystal structure of an affinity-matured prolactin complexed to its dimerized receptor reveals the topology of hormone binding site 2. J Biol Chem 2010;285:842233.
13. Kulkarni MV, Tettamanzi MC, Murphy JW, et al. Two independent histidines, one in human prolactin and one in its receptor, are critical for $\mathrm{pH}$-dependent receptor recognition and activation. J Biol Chem 2010;285:38524-33.

14. Brooks CL. Molecular mechanisms of prolactin and its receptor. Endocr Rev 2012;33:504-25.

15. O'Shea JJ, Holland SM, Staudt LM. JAKs and STATs in immunity, immunodeficiency, and cancer. N Engl J Med 2013; 368:161-70.

16. Fang F, Antico G, Zheng J, Clevenger CV. Quantification of PRL/Stat5 signaling with a novel pGL4-CISH reporter. BMC Biotechnol 2008;8:11.

17. Thakker RV, Newey PJ, Walls GV, et al. Clinical practice guidelines for multiple endocrine neoplasia type 1 (MEN1). J Clin Endocrinol Metab 2012;97:2990-3011.

18. Rao GV, Brooks CL. Functional epitopes for site 1 of human prolactin. Biochemistry 2011;50:1347-58.

19. Dagil R, Knudsen MJ, Olsen JG, et al. The WSXWS motif in cytokine receptors is a molecular switch involved in receptor 
activation: insight from structures of the prolactin receptor. Structure 2012;20:270-

82.

20. Bogorad RL, Courtillot C, Mestayer C, et al. Identification of a gain-of-function mutation of the prolactin receptor in women with benign breast tumors. Proc Natl Acad Sci U S A 2008;105:14533-8.

21. Horseman ND, Zhao W, MontecinoRodriguez E, et al. Defective mammopoiesis, but normal hematopoiesis, in mice with a targeted disruption of the prolactin gene. ЕMBO J 1997;16:6926-35.

22. Bouchard B, Ormandy CJ, Di Santo JP, Kelly PA. Immune system development and function in prolactin receptor-deficient mice. J Immunol 1999;163:576-82.

23. Ormandy CJ, Camus A, Barra J, et al. Null mutation of the prolactin receptor gene produces multiple reproductive defects in the mouse. Genes Dev 1997;11 167-78.
24. Binart N, Bachelot A, Bouilly J. Impact of prolactin receptor isoforms on reproduction. Trends Endocrinol Metab 2010;21: 362-8.

25. Li W, Ma N, Laird SM, Ledger WL, Li TC. The relationship between serum prolactin concentration and pregnancy outcome in women with unexplained recurrent miscarriage. J Obstet Gynaecol 2013; 33:285-8.

Copyright @ 2013 Massachusetts Medical Society. 